\title{
Analysis by GC-MS of monocyclic and polycyclic aromatic hydrocarbons in thermolysed waste products
}

\author{
B. Disdier*, C. Arfi, J. Pastor, A.M. Pauli and H. Portugal \\ Laboratoire de chimie analytique, Faculté de Pharmacie, 13000 Marseille, France
}

\begin{abstract}
Thermolysis is a new thermal decomposition process of waste products involving partial vacuum and oxygen free environment. The GC-MS study covered 5 monocyclic and 16 polycyclic aromatic hydrocarbons produced by the thermolysis of four samples (three samples from domestic wastes and one sample from pneumatic wastes). Qualitative results were similar for all of the four samples: benzene, toluene, xylenes, styrene, naphtalene, biphenyl, fluorene, phenanthrene, anthracene, fluoranthene and pyrene were found. None of the most toxic such as benzo[a]pyrene and 1,2 benzanthracene were found. Quantitative results were relatively homogeneous for the first three samples ( $<10 \mathrm{ng} \mathrm{g}^{-1}$ for all of the compounds) but concentrations of hydrocarbons were higher (4 to 9 times) for pneumatic wastes samples. Naphtalene remained the most abundant polycyclic aromatic hydrocarbon in any case.
\end{abstract}

Key words. Monocyclic aromatic hydrocarbons (MAH) - polycyclic aromatic hydrocarbons (PAH) - thermolysis - GC-MS.

\section{Introduction}

Thermolysis is a new thermal decomposition process of waste products. This process involves a partial vacuum and oxygen free environment inerted under a stream of nitrogen. This technique allows for the recuperation and valorisation of recyclable materials without producing any dust or clinkers. Wastes decomposition is carried out in an oven in presence of recycled gas of thermolysis, circulating in a continuous flow, at $650{ }^{\circ} \mathrm{C}$. Gas issued from thermolysis are cooled and treated: gaseous fraction is directly used as energy source and, water and hydrocarbon fractions are collected after decantation on a lamellar layer separator. Hydrocarbons are conditionned to be used in the thermal cycle as an energy source. So it is important to know the nature and the rates of these hydrocarbons in order to anticipate the degree of risk for the environment and to evaluate the best conditions of their recycling.

The aim of this study was to analyse these hydrocarbons, obtained after thermolysis of waste compounds. Monoaromatic hydrocarbons (MAH) and polyaromatic hydrocarbons (PAH) are known to be toxic compounds, bronchopulmonary and cutaneous irritants, with risks of carcinogenicity and mutagenicity. Cases of cutaneous, bronchopulmonary and vesical tumors have been linked with aromatic hydrocarbons. The degree of risk depends on the compounds, benzo[a]pyrene is shown to be the most toxic $[1,2]$.

Several methods have been described for aromatic hydrocarbons determination. The most developed techniques were suitable for analysis in liquid oily matrices [3,4] or aqueous matrices [5-7]. These methods were essentially liquid chromatography with spectrofluorimetric, spectrophotometric UV or mass spectrometric detection. Nevertheless these methods involved preconcentration stages, for samples with low rates of hydrocarbons. Immunoenzymatic methods were also developed $[8,9,10]$, but some PAH were lost due to their adsorption in the layer of polymer used for the test [8]. Only a few methods were described for the analysis of hydrocarbons in semi solid or solid matrices such as sludges and contaminated soils [11,12]. Gas chromatography coupled with mass spectrometry (GC-MS) is the standard method for the analysis of aromatic hydrocarbons in complex matrices. The interest of mass spectrometry detection in comparison with flame ionisation was demonstrated, for PAH analysis in complex matrices, by Baumard et al. [13]. This sensitive and selective method was choosen for our study, the qualitative and quantitative analysis of hydrocarbons (MAH and PAH) in thermolysed wastes products, domestic and pneumatic wastes.

\section{Materials and methods}

\section{Samples}

Samples were collected at the end of thermolysis cycle after decantation on a lamellar layer separator either from domestic wastes, or from pneumatics.

In case of domestic wastes, three samples were collected at the end of three different thermolysis cycles with each cycle using different random waste samples (samples 1, 2 and 3). Domestic thermolysed wastes were issued from Marseilles surroundings; their composition was variable: dry 


\section{Original articles}

organic materials, glass, dust and metal. Although the proportion of each component was not determined for this study.

In case of pneumatics, only one thermolysed sample was obtained (sample 4).

For every waste used at the head of thermolysis cycle, the consistency of the obtained residues was pasty and black colored.

Exact weighings of approximate $2 \mathrm{~g}$ samples were tested three times for each sample to carry out the analysis in triplicate.

\section{Standards and solvents}

Standards choosen for analysis were:

Five MAH: phenol, benzene, toluene, xylenes (para, meta, ortho), styrene.

Sixteen PAH: naphthalene, biphenyl, acenaphthene, fluorene, phenanthrene, anthracene, carbazol, fluoranthene, pyrene, 2,3-benzofluorene, chrysene, 1,2-benzanthracene, benzo[k]fluoranthene, benzo[e]acephenanthrylene, benzo[a]pyrene, indeno-1,2,3-pyrene.

The PAH were studied for all of the samples collected, and the MAH were only studied for residues of thermolysis of domestic wastes.

Hydrocarbons studied were selected because of their representative toxic risk. Most of them are included in the priority pollutant list, given by the US Environmental Protection Agency (US EPA). Among these compounds, four PAH (fluoranthene, benzo[k]fluoranthene, benzo[a]pyrene, indeno-1,2,3-pyrene) were considered by the World Health Organisation and the European Union as pollution tracers in natural and drinking waters.

Standard products were supplied by Merck (Darmstadt, Germany), hexane by SDS (Peypin, France) and pyridine by Carlo Erba, (Milan, Italy). All chemicals used in this study were of analytical reagent grade.

MAH or PAH (200 mg) were dissolved in $20 \mathrm{~mL}$ hexane or pyridine respectively to give a concentration of $10 \mathrm{mg}$ $\mathrm{mL}^{-1}$. These solutions were further diluted to give the required concentrations.

\section{Extraction}

Most of the extraction procedures developed for hydrocarbons involve organic solvents. Soxhlet extraction is the reference method, but manipulations are time consuming (8-48 h) and require high amounts of solvents and so a high cost for analysis [14,15]. More recent methods, supercritical fluids extraction or accelerated solvent extraction, were suitable to reduce extraction time (less than 90 min [10]) and to optimize recovery [11]. The selected ultrasonic extraction using organic solvents combines effectiveness with simplicity and speed. So, it has been successfully applied to the extraction of PAH from airborne particulate matters and sediments [17-19] and from waste waters and sewage sludge with recoveries (69 to 127\%) according to the applied procedure (solvent, time) [12].

In our study, PAH samples were prepared in pyridine which is the best solvent for solubilisation and extraction of high molecular mass hydrocarbon fractions [20]. MAH samples were prepared in hexane (boiling point $69^{\circ} \mathrm{C}$ ) because the pyridine boiling point $\left(110{ }^{\circ} \mathrm{C}\right)$ is higher than low molecular mass hydrocarbons as MAH. So, chromatographic interferences of analytes and solvent were avoided.

Thermolysis residues samples were extracted by ultrasonic treatment in appropriate solvents during $30 \mathrm{~min}$ as described elsewhere for matrices of similar consistency (coal tar pitch) $[20,21]$. The extracts were filtered $(0.45 \mu \mathrm{m})$ under vacuum to eliminate all solid particles.

\section{Chromatographic conditions}

GC-MS was carried out using total ion monitoring mode on a Varian 3400 gas chromatograh interfaced to a Varian Saturn ion trap 4D GC/MS/MS mass spectrometer. The temperatures of transferline and ion source were $285{ }^{\circ} \mathrm{C}$ and $175^{\circ} \mathrm{C}$ respectively. The HP-5MS column $(30 \mathrm{~m} \times 0.22 \mathrm{~mm}$ I.D., $1.0 \mu \mathrm{m}$ film thickness) coated with cross-linked $5 \%$ phenyl methyl silicone was used. A splitless injection mode was selected with a solvent delay time of $3 \mathrm{~min}$. The initial temperature of the column was held at $50{ }^{\circ} \mathrm{C}$ for $1 \mathrm{~min}$ programmed at $2.5{ }^{\circ} \mathrm{C} \mathrm{min}{ }^{-1}$ to $250{ }^{\circ} \mathrm{C}$ for toluene and at $100{ }^{\circ} \mathrm{C}$ for $1 \mathrm{~min}$ programmed at $10^{\circ} \mathrm{C} \mathrm{min}^{-1}$ to $285^{\circ} \mathrm{C}$ for PAH. Injection port was set at $110{ }^{\circ} \mathrm{C}$ and $255^{\circ} \mathrm{C}$ for toluene and PAH respectively. Helium was used as carrier

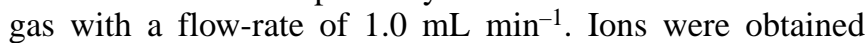
by electronic impact. Molecular ions were monitored for quantification.

\section{Qualitative analysis}

The chromatographic separation was controlled by resolution factor (Rs) calculation.

Identification of separated compounds was achieved by retention times in comparison with respective standards and by mass spectra comparison (standards and Wiley library).

\section{Quantitative analysis}

Quantified MAH was toluene and quantified PAH were naphthalene, biphenyl, fluorene and phenanthrene. Calibration curves were obtained by plotting the peak-area of hydrocarbon versus the amounts of hydrocarbon $\left(0.1-0.25-0.5-0.75-1-4 \mathrm{mg} \mathrm{mL}^{-1}\right.$ for PAH and 1-2.5-5-7.5-10 $\mathrm{mg} \mathrm{mL}^{-1}$ for toluene). For toluene over the range $1-10 \mathrm{mg} \mathrm{mL}^{-1}$, a linear fit was satisfactory with a $r$ of 0.972 . For PAH over the range $0.1-4 \mathrm{mg} \mathrm{mL}^{-1}$ the $r$ was $0.994-0.991-0.991-0.992$ for naphtalene, biphenyl, fluorene and phenanthrene respectively. 


\section{Results - discussion}

\section{Qualitative analysis}

Retention times and resolution factors are resumed in table I.

For the MAH, Rs values were always > 1.5 except for styrene (retention time $=684 \mathrm{~s}$ ) and orthoxylene (retention time $=687 \mathrm{~s}$ ) with $\mathrm{Rs}=0.17$. So, identification of each of them, was done by a standard spiked sample. Retention times were over the range $196 \mathrm{~s}$ (benzene) to $961 \mathrm{~s}$ (phenol) for the MAH (Fig. 1a).

All the PAH were well separated in the above described chromatographic conditions. Indeed, all of the Rs values were > 1.5. Retention times were over the range $462 \mathrm{~s}$ (naphtalene) to $3049 \mathrm{~s}$ (indeno-1,2,3-pyrene) (Fig. 1b). Qualitative analysis showed that composition of thermolysis residues of domestic wastes from three different cycles (samples 1, 2 and 3) was almost the same. Each sample was analysed in triplicate and showed similar results. In the three samples the found MAH were: toluene, xylenes (ortho, meta, para) and styrene. No traces of phenol was detected. Very low quantities of benzene were identified by a standard spiked sample (Tab. I). The found and directly identified PAH in all the samples were: naphtalene, biphenyl, fluorene and phenanthrene. Anthracene and pyrene were present but in very low quantities and had to be identified after a standard spiked sample. Fluoranthene was directly identified in samples 1 and 2 but a standard spiked sample was necessary for identification in sample 3. Chrysene was present in sample 2 only. No traces of the other studied PAH were detected, and in particular the most toxic hydrocarbons were not found: benzo[a]pyrene and 1,2-benzanthracene [1,2]. Among the four pollution tracers, only fluoranthene was found in very low rates.

Qualitative analysis of PAH in the thermolysis residues of pneumatics was done in triplicate and results were the same for the three trials. The identified hydrocarbons in this case were the same than those found for thermolysis residues of domestic wastes: naphthalene, biphenyl, fluorene, phenanthrene, anthracene, fluoranthene and pyrene. The other studied hydrocarbons were not detected.

These data have to be compared with those obtained during previous studies in polluted matrices such as waste waters, sewage sludge [12], and soils [11]. Naphtalene, fluorene, phenanthrene, were found in thermolysis residues and

Table I. Qualitative analysis

\begin{tabular}{|c|c|c|c|c|c|c|}
\hline & Retention time $(s)$ & Resolution factor (Rs) & $\begin{array}{c}\text { Samples } \\
\text { Domestic } \\
1\end{array}$ & $\begin{array}{c}\text { Wastes } \\
2\end{array}$ & 3 & $\begin{array}{c}\text { Pneumatics } \\
4\end{array}$ \\
\hline \multicolumn{7}{|c|}{ Monoaromatic hydrocarbons } \\
\hline benzene & 196 & & + & + & + & ND \\
\hline toluene & 354 & $\begin{array}{l}10 \\
18\end{array}$ & + & + & + & ND \\
\hline paraxylene & 590 & $\begin{array}{l}18 \\
16\end{array}$ & + & + & + & ND \\
\hline metaxylene & 617 & $\begin{array}{l}1.6 \\
3.3\end{array}$ & + & + & + & ND \\
\hline styrene & 684 & 3.3 & + & + & + & ND \\
\hline orthoxylene & 687 & 0.17 & + & + & + & ND \\
\hline phenol & 961 & & - & - & - & ND \\
\hline \multicolumn{7}{|l|}{ Polyaromatic hydrocarbons } \\
\hline naphthalene & 462 & & + & + & + & + \\
\hline biphenyl & 631 & $\begin{array}{l}19.3 \\
17.2\end{array}$ & + & + & + & + \\
\hline acenaphthene & 786 & 17.2 & - & - & - & - \\
\hline fluorene & 813 & $\begin{array}{c}3 \\
18\end{array}$ & + & + & + & + \\
\hline phenanthrene & 976 & & + & + & + & + \\
\hline anthracene & 980 & $\begin{array}{l}1.5 \\
5.9\end{array}$ & + & + & + & + \\
\hline carbazole & 1033 & $\begin{array}{l}5.9 \\
7.4\end{array}$ & - & - & - & - \\
\hline fluoranthene & 1166 & $\begin{array}{l}7.4 \\
4.4\end{array}$ & + & + & + & + \\
\hline pyrene & 1206 & $\begin{array}{l}4.4 \\
8.8\end{array}$ & + & + & + & + \\
\hline 2,3-benzofluorene & 1285 & $\begin{array}{l}8.8 \\
24\end{array}$ & - & - & - & - \\
\hline chrysene & 1502 & 24 & - & + & - & - \\
\hline 1,2-benzanthracene & 1547 & $\begin{array}{c}5 \\
44\end{array}$ & - & - & - & - \\
\hline benzo[k]fluoranthene & 1943 & 44 & - & - & - & - \\
\hline benzo[e]acephenanthrylene & 1965 & $\begin{array}{ll}2.4 \\
22\end{array}$ & - & - & - & - \\
\hline benzo[a]pyrene & 2164 & $\begin{array}{l}22 \\
08\end{array}$ & - & - & - & - \\
\hline indeno-1,2,3-pyrene & 3049 & 98 & - & - & - & - \\
\hline
\end{tabular}

+: present; -: absent; ND: not determined. 


\section{Original articles}

a)
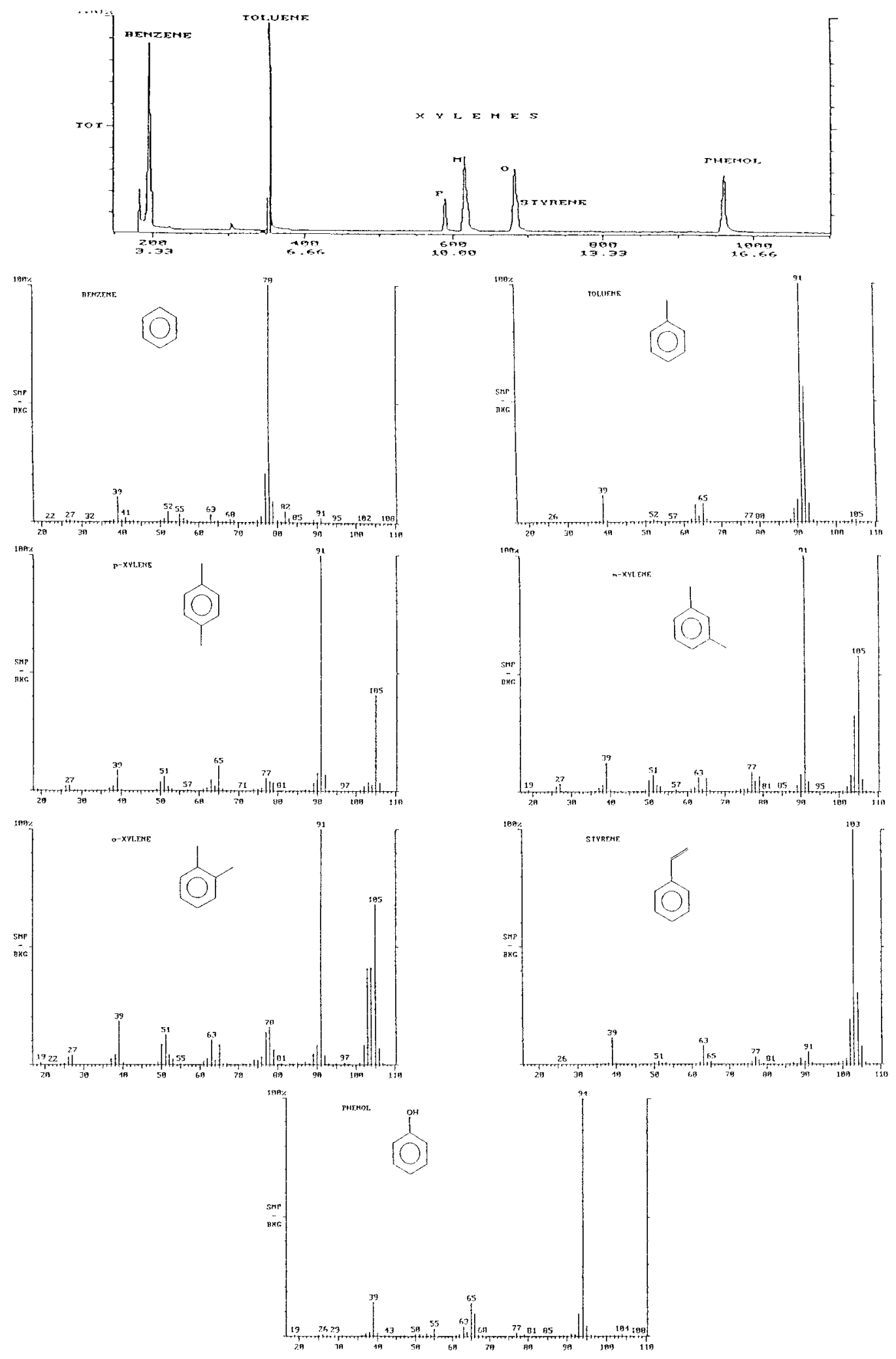
b)
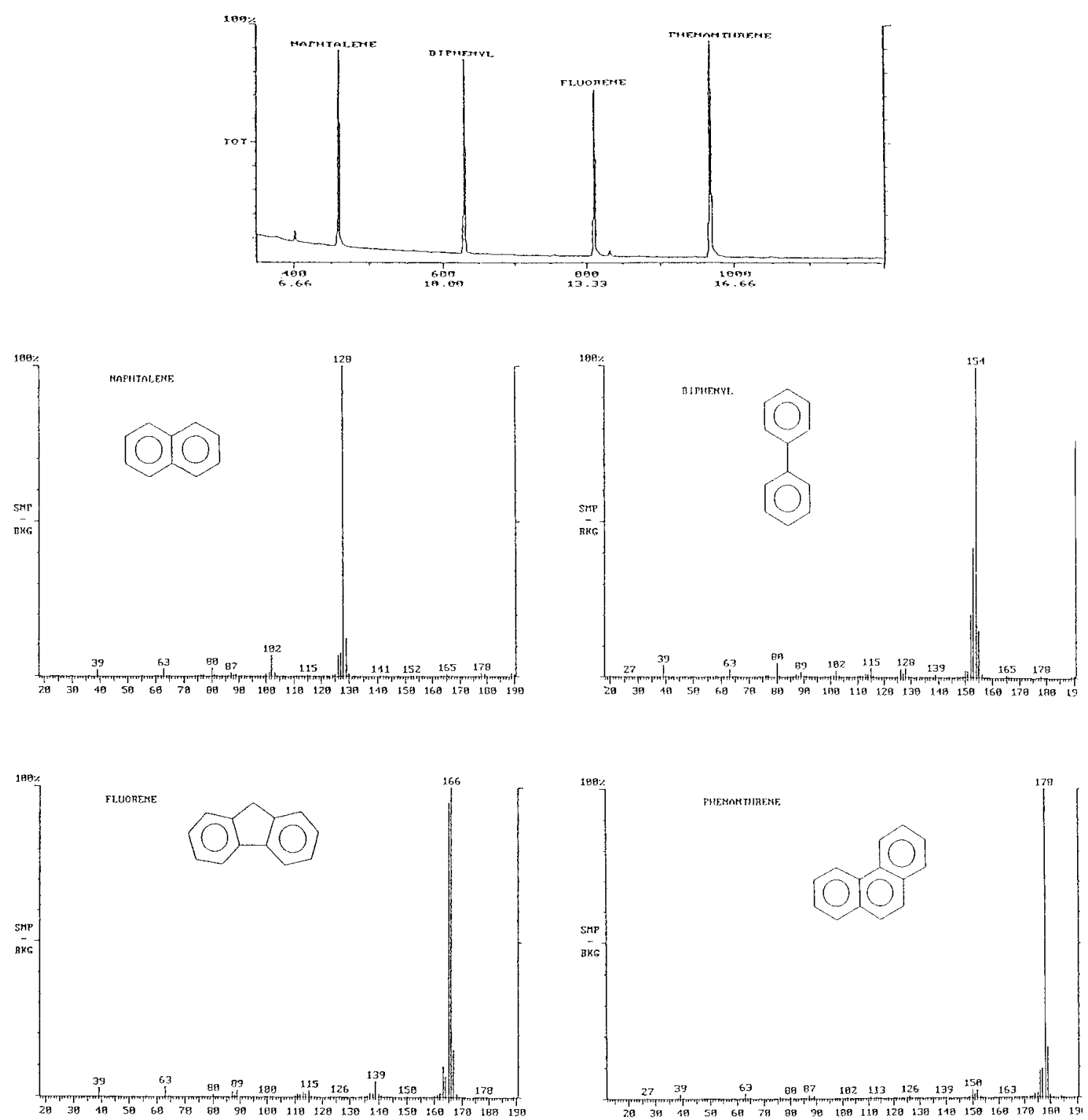

Fig. 1. a) Chromatograms and mass spectra of a standard solution of monoaromatic hydrocarbons: benzene, toluene, p-xylene, m-xylene, o-xylene, styrene, phenol. b) Chromatograms and mass spectra of a standard solution of polyaromatic hydrocarbons: naphtalene, biphenyl, fluorene, phenanthrene.

in polluted matrices. The most toxic hydrocarbons and pollution tracers (pyrene, chrysene, benzanthracene, benzo[a]pyrene, fluoranthene, benzo[k]fluoranthene and indeno-1,2,3-pyrene), always present in waste waters, sewage sludge and polluted soils, were absent in the thermolysis residues. The number of hydrocarbons appeared to be lower in thermolysis residues than in contaminated matrices, particularly for the most toxic compounds, and pollution tracers.

\section{Quantitative analysis}

The results obtained for toluene (MAH), and naphthalene, biphenyl, fluorene, phenanthrene (PAH) are presented in table II.

\section{Domestic wastes (samples 1, 2, 3)}

For the thermolysis residues of domestic wastes, all of the assays were done in triplicate and there was a good 


\section{Original articles}

Table II. Mean concentrations of studied hydrocarbons in thermolysis residues $(n=3)$.

\begin{tabular}{|c|c|c|c|c|}
\hline & \multirow[b]{2}{*}{$\begin{array}{c}\text { Domestic wastes } \\
\text { Sample } 1\end{array}$} & \multicolumn{2}{|c|}{ Concentrations $\left(\mathrm{mg} \mathrm{g}^{-1}\right)$} & \multirow[b]{2}{*}{$\begin{array}{l}\text { Pneumatics } \\
\text { Sample } 4\end{array}$} \\
\hline & & $\begin{array}{c}\text { Domestic wastes } \\
\text { Sample } 2\end{array}$ & $\begin{array}{c}\text { Domestic wastes } \\
\text { Sample } 3\end{array}$ & \\
\hline Naphthalene & 0.870 & 1.200 & 1.300 & 4.660 \\
\hline Biphenyl & 0.290 & 0.470 & 0.510 & 2.520 \\
\hline Fluorene & 0.100 & 1.000 & 0.150 & 1.740 \\
\hline Phenanthrene & 0.085 & 0.110 & 0.190 & 0.833 \\
\hline Toluene & 1.510 & 2.300 & 5.180 & ND \\
\hline
\end{tabular}

$\mathrm{ND}=$ not determined

reproducibility of the results with coefficients of variation between 3 and $8 \%$; coefficients of variations were established on three determinations and the values are mentioned only for guidance. The three samples concentrations were $<10 \mathrm{mg} \mathrm{g}^{-1}$ for all of the studied compounds. Toluene concentrations were higher (2-5 times) than all the PAH. Toluene concentration was much higher in sample 3 than in samples 1 and 2 .

For the PAH, the obtained values were relatively homogeneous between the three samples, with maximal concentrations found for naphtalene. For fluorene, almost similar concentrations were found in samples 1 and 3 but a concentration of 10 times as high was found in sample 2 . The other compounds, classified in increasing order of concentrations are as follows: phenanthrene, biphenyl and naphthalene. Therefore some differences were observed, for fluorene in sample 2 and toluene in sample 3. Those disparities may be due to differences of sampling issued from three different thermolysis cycles, with initial domestic wastes not being exactly similar in their organic materials composition.

\section{Pneumatics (sample 4)}

Concentrations of hydrocarbons for thermolysis residues of pneumatics were much higher than for thermolysis residues of domestic wastes: about 4 times for naphtalene, 7 times for biphenyl, 9 times for fluorene and 7 times for phenanthrene. Naphthalene remained,in any case, the most abundant $\mathrm{PAH}$.

In the literature, PAH concentrations in polluted natural matrices like soils [11], waste waters and sewage sludge [12] ranged from $\mathrm{ng} \mathrm{g}^{-1}$ to $\mu \mathrm{g} \mathrm{g}^{-1}$. Results obtained in thermolysis residues were about $\mathrm{mg} \mathrm{g}^{-1}$, so $10^{3}$ to $10^{6}$ times higher than in polluted natural matrices. They should therefore not be rejected in the environment, which would pollute. Therefore, valorisation of those residues by direct use in thermolysis cycle as energy source is interesting and necessary. Furthermore, those relatively high concentrations of hydrocarbons are a favorable factor for recycling, due to their high energizing power.

\section{Conclusion}

The use of gas chromatography coupled with mass spectrometry was suitable for qualitative and quantitative studies of monoaromatic and polyaromatic hydrocarbons in thermolysis residues of wastes. The identification and the quantification of hydrocarbons in those residues, participate in environmental risk evaluation and enable their energizing power calculation for effective recycling. This method could be extrapolated to other products of thermal degradation during industrial processes.

\section{Acknowledgments}

A. Crestin for technical assistance and D. Bonnet, J. Riou, J.C. Sari for supplying samples.

\section{References}

1. IARC Monographs on the evaluation of the carcinogenic risk of chemicals to human volume 32, IARC Lyon 1983.

2. INRS Paris, Fiches toxicologiques: FT 91: brai de houille, FT 144: benzo[a]pyrène, FT 204: naphtalène, 1987, FT 15: phénol, 1988, FT 2: styrène, FT 49: benzène, FT 77: toluène et xylènes, 1992.

3. Jadaud, P.; Caude, M.; Rosset R. Analusis 1986, 14(10), 491507.

4. Colin, J. M.; Vion, G. Analusis 1980, 8(6), 224-229.

5. Norme AFNOR T 90-115 septembre 1988.

6. Fladung, N. C. J. Chromatogr. A 1995, 692, 21-26.

7. Kiss, G.; Varga-Puchony, Z.; Havlay, J. J. Chromatogr. A 1996, 725, 261-272.

8. Quelven, E.; Mille, G.; Fourneron, J. D. Analusis 1997, 25, $48-50$.

9. Mahaffey, W. R.; Compeau, G.; Nelson, M. Water Environ. Technol. 1991, 83-88.

10. Wild S. R.; Jones, K. C. Sci. Tot. Environ. 1992, 119, 85-119.

11. Popp, P.; Keil, P.; Möder, M.; Paschke, A.; Thuss, U. J. Chromatogr. A 1997, 774, 203-211.

12. Manoli, E.; Samara, C. Chromatographia 1996, 43(3/4), 135142.

13. Baumard, P.; Budzinski, H. Analusis 1997, 25, 246-252.

14. Bossert, I.; Kachel, W. M.; Bartha, R. Appl. Environ. Microbiol. 1984, 47, 763-767.

15. Oudot, J. Analusis 1994, 22, 16-18. 
16. Rodriguez, C.; Bispo, A.; Haag, J. L.; Chollot, A.; Jauzein, M.; Colin, F. Analusis Magazine 1997, 25(9-10), 53-59.

17. Hicinski, H. G.; Adamek, S.; Kettrup, A. Chromatographia 1989, 28, 203-209.

18. Manoli, E.; Samara, C. Fresenius Environ. Bull. 1994, 4, 7476.
19. Marvin, C. H.; Allan, L.; Mc Carry, B. E.; Bryant, D. W. Int. J. Environ. Anal. Chem. 1992, 49(4), 221-225.

20. Blanco, J.; Guillen, M. D. Energy \& Fuels 1991, 5, 188-192.

21. Blanco, C. G., Canga, J. S., Dominguez, A., Iglesias, M. J., Guillen, M. D. J. Chromatogr. 1992, 607, 295-302. 